\title{
BMJ Global Health International migration and health: it is time to go beyond conventional theoretical frameworks
}

\author{
Muhammad Zakir Hossin (D) 1,2,3
}

To cite: Hossin MZ. International migration and health: it is time to go beyond conventional theoretical frameworks. BMJ Global Health 2020;5:e001938. doi:10.1136/ bmjgh-2019-001938

\section{Handling editor Seye Abimbola}

Received 23 August 2019 Revised 5 February 2020 Accepted 7 February 2020
Check for updates

C) Author(s) (or their employer(s)) 2020. Re-use permitted under CC BY-NC. No commercial re-use. See rights and permissions. Published by BMJ.

${ }^{1}$ Department of Global Public Health, Karolinska Institute, Stockholm, Sweden ${ }^{2}$ Department of Public Health Sciences, Stockholm University, Stockholm, Sweden

${ }^{3}$ Department of General Education, Eastern University Bangladesh, Dhaka, Bangladesh

Correspondence to Muhammad Zakir Hossin; zakir.hossin@ki.se

\section{ABSTRACT}

The large-scale international migration in the 21st century has emerged as a major threat to the global health equity movement. Not only has the volume of migration substantially increased but also the patterns of migration have become more complex. This paper began by focusing on the drivers of international migration and how health inequalities are linked to migration. Situating migration within the broader structural contexts, the paper calls for using the unharnessed potential of the intersectionality framework to advance immigrant health research. Despite coming from poorer socioeconomic backgrounds and facing disparities in the host society, the immigrants are often paradoxically shown to be healthier than the native population, although this health advantage diminishes over time. Studies on immigrant health, however, are traditionally informed by the acculturation framework which holds the assimilation of unhealthy lifestyles primarily responsible for immigrant health deterioration, diverting the attention away from the structural factors. Although the alternative structural framework came up with the promise to explore the structural factors, it is criticised for an overwhelming focus on access to healthcare and inadequate attention to institutional and societal contexts. However, the heterogeneity of the immigrant population across multiple dimensions of vulnerability demands a novel approach that can bring to the fore both premigratory and postmigratory contextual factors and adequately capture the picture of immigrant health. The paper concludes by questioning the acculturation perspective and pushing the structural paradigm to embrace the intersectionality framework which has the potential to address a wide range of vulnerabilities that intersect to produce health inequalities among the immigrants.

\section{INTRODUCTION}

There has been a dramatic increase in international migration over the last two decades, and it is continuously on the rise in an increasingly globalised context with substantial implications for population health policy and research. The number of international migrants was estimated to be 272 million in 2019-up from 244 million in $2015 .{ }^{1}$ While a negative view towards immigration is growing

\section{Summary box}

- The rapid growth of international migrants in a globalised context and the heterogeneity of immigrant populations pose a big challenge to public health policy and research.

- The empirical literature on immigrant health broadly showcase a 'healthy immigrant effect', with concurrent evidence of downward health trajectory over time.

- From the acculturation perspective, the assimilation of unhealthy behaviours is to blame for immigrants' downward health trajectory while the traditional structural framework attributes it to restricted access to healthcare.

- Immigration itself is determined by economic, social, political and environmental factors, and hence its association with health cannot be clearly understood independent of the upstream causal forces.

- The modern intersectionality framework has the potential to advance immigrant health research through a simultaneous focus on multiple dimensions of systematic vulnerabilities and discrimination.

at a global level with people in many destination countries, especially in Europe and America, preferring to decrease their current level of immigration, ${ }^{2}$ the number of international migrants is projected to reach a staggering 405 million in 2050 and the current rate of increase has even surpassed the previous projection due to the large-scale displacements occuring globally in most recent years. ${ }^{1}$ The forces of globalisation, economic pressures, climate change and environmental degradation, political violence and human rights abuses are said to be the major drivers of this unprecedented human mobility worldwide. ${ }^{13}$

If the international migrants were to comprise a nation state, it would be the fifth largest country on the planet in terms of the size of the population. Although human mobility is not a new phenomenon, the rapid increase of the worldwide migration flows in the contemporary world has no precedence 
in human history. Not only the migration flows that have substantially gone upward but also the patterns of migration have themselves become more complex and diversified over time, necessitating an increased attention to the determinants of migration.

While the lives of the immigrants are shaped by social, economic and political structures, policies and institutions in their homelands, they experience new sociopolitical and economic conditions in the countries of destination where they live under discriminatory policies and often lack access to critical health resources. ${ }^{4}$ Migration is thus accompanied by enormous consequences on the daily lives of the people who migrate and is often shown to be negatively associated with adverse health risks and outcomes. ${ }^{56}$ However, most studies examining the association between migration and health tend to overlook the immigrants' migratory experiences and background circumstances from the country of origin. ${ }^{7}$ This is a serious cause for concern since any association between a postmigration experience and health might theoretically be confounded by the events experienced prior to or during migration. Drawing on existing literature, the current paper aims to:

- Provide an overview of the major forces that drive the cross-border population movements and how health inequalities are shaped by the structural processes of immigration and marginalisation.

- Present a critique of the two theoretical frameworks that are commonly used to explain the health status of immigrant populations: the cultural framework and the structural framework.

- Highlight the potential of the intersectionality framework to better document and understand immigrant health.

\section{WHAT DRIVES MIGRATION INTERNATIONALLY?}

The dynamics of population movements are quite complex and varied. The key issues are whether such movements are internal displacements or cross-border movements, whether the decision to migrate is forced or voluntary and whether migration takes the form of temporary, circular or permanent movements. ${ }^{8}$ Whatever the type of migration is, the core choice involves calculating the risks and benefits of moving versus staying and the ultimate decision to move may be influenced by a wide range of economic, social, demographic, political and environmental factors which include improving income and standards of living, pursuing quality education, getting reunited with family members, escaping political persecution and getting rid of environmental threats. None of these factors, however, act in isolation; they tend to operate in combination with each other. Also, the effects of these factors on migration are likely to be confounded by the migrant's personal circumstances such as class, ethnicity, religion, language, cost of moving, social networks and the immigration laws. ${ }^{9} 10$
As migration has emerged as a global phenomenon at the turn of the 21st century, globalisation provides the key context for understanding the international migration flows. While globalisation is said to be positively associated with overall economic development further bringing with it a variety of social, political and health benefits, ${ }^{11}$ the benefits are disproportionately distributed across national borders. This 'asymmetrical' character of contemporary globalisation exacerbates social and economic inequities both between and within countries. ${ }^{12}$ International migration can be seen as a reflection of global inequalities between countries. To the extent that migration is primarily driven by economic incentives, global income inequality serves as a major 'push factor' that motivates people to emigrate in order to look for opportunities elsewhere. As Black and colleagues ${ }^{13}$ have so aptly put it: 'International migration is a powerful symbol of global inequality, whether in terms of wages, labour market opportunities, or lifestyles. Millions of workers and their families move each year across borders and across continents, seeking to reduce what they see as the gap between their own position and that of people in other, wealthier, places.' Today, globalisation has made international transportation and communication much faster and easier than ever before. As a result, not only has the scale of international migration accelerated but also the character of migration flows has altered substantially-from the typically permanent migrations of the past to the circular or temporary migrations in current times. $^{1415}$

In concert with the accelerating pace of globalisation processes, climate change or environmental degradation has emerged as a leading trigger factor of migration in recent times and is predicted to give rise to even greater population movements in the coming years. By the middle of the current century, the number of environmental migrants, both internally displaced and international, is estimated to reach as high as 250 million, ${ }^{8}$ a figure which outnumbers the current stock of international migrants. Throughout human history, migration has always been an important adaptation strategy in response to adverse environmental conditions. Whereas the internally displaced people constituted the vast majority of environmental migrants in the past, the volume of international movements is of increasing significance. ${ }^{16}$ Moreover, in contrast to the historical experience of mass displacements resulting from natural environmental disasters, today the world has started witnessing a new trend of population movements due to human-induced climate change. Global warming and its inevitable product - the rise of sea levels-is the predominant feature of this climate change which is primarily driven by human-generated emissions of greenhouse gases. However, climate change itself may rarely be directly linked to international displacements but is likely to exacerbate the existing vulnerabilities and generate slow onset environmental effects (eg, drought, rising sea levels, land degradation) which in turn may affect 
the livelihoods of people, their migration behaviour and health and well-being. ${ }^{8}$

\section{IMMIGRATION, 'OTHERING’ AND HEALTH INEQUALITIES}

'Othering' is a process that effectively sets up a distance between 'us' and 'them' and the individuals positioned as the 'other' experience this as a 'process of marginalisation, disempowerment and social exclusion'. ${ }^{17}$ ViruellFuentes ${ }^{18}$ points to the potential pathways through which 'othering' might affect the health of the immigrants and their descendants. Viruell-Fuentes argues that 'othering' is a function of structural racism and as such contributes to the shaping of the ethnic/racial status of the immigrants. This in turn influences the more proximate pathways to health including stress, fear, experience of prejudice and violence, access to healthcare, safe work and housing. Consequently, the immigrants are more likely to be unemployed, work in low paid jobs, end up in low status neighbourhoods and report poorer health than the native population. ${ }^{5}$

While all migrants might be the victims of the 'othering' process, the forced migrants such as the refugees, asylum seekers and irregular migrants are more likely to experience it than voluntary migrants. Grove and $\mathrm{Zwi}^{17}$ highlighted how the forced migrants are constructed as the 'other' in their place of destination and are systematically set apart from the mainstream society. Forced migrants typically flee away from countries where access to healthcare is limited and exposure to ill-health is substantial. Each stage of the journey of forced migrants-predeparture, travel, arrival and return-is accompanied by health hazards. Their journey to the host country is often dangerously prolonged and marked by an ongoing fear of uncertainty, anxiety, insecurity, separation from family, exploitation, lack of food and shelter, sexual abuse, violence, injury and even deaths. ${ }^{19}$ These prior exposures of the migrants are further exacerbated by the process of 'othering' and have profound implications for immigrant health and well-being.

Refugees and asylum-seekers are rarely perceived as the carriers of skills and capacities to the new society; they are rather perceived as a threat to national security and 'vectors of infectious diseases' which in turn leads to a focus on the protection from the refugees instead of protection of the refugees. This is clearly reflected in the complex security measures including heightened level of frontier control, restricted visas, screening, deterring, detention and so forth. ${ }^{17}$ Even when the migrants are welcomed, the fear of repatriation and concerns about future safety and security persist. Empirical evidence suggests that the sustained periods of severe stress before, during and after the migration leads to the development of mental illnesses including depression and post-traumatic stress disorders. ${ }^{5}$ This is particularly problematic for the undocumented migrants who remain excluded from the health, welfare and social services for a prolonged period of time. Moreover, the vulnerability to illness due to the structural process of 'othering' may be further compounded by the background characteristics of the migrants (eg, gender, age, disability status, class, geography and religion), putting certain groups of migrants at greater risks than others. ${ }^{3}$

Majority of the existing body of literature linking migration to health lend support to the so-called 'healthy immigrant effect' hypothesis which postulates that the health of immigrants is significantly better in comparison with their native counterparts in terms of mortality, chronic diseases and mental health outcomes. ${ }^{60-29}$ Such a pattern of health appears to be paradoxical given the relatively poor socioeconomic background of the immigrants as well as the socioeconomic disparities they face in the receiving country. The healthy migrant effect is typically attributed to the process of selective out-migration (ie, only the healthier people are led to migrate). ${ }^{22}{ }^{23}{ }^{30} \mathrm{~A}$ further hypothesis proposed to explain the lower mortality among immigrants underlies the concept of 'salmon bias' which suggests that the socio-economically unsuccessful immigrants with a higher risk of mortality have a tendency to return to their home country, leading to an underestimation of migrant mortality in the host country. ${ }^{31-33}$ The reported health advantage of the immigrants, however, does not usually persist over time. Several studies, for instance, indicate that the immigrants living for several years in the host country have worse health than the newly arrived immigrants or the native population, implying an erosion of immigrant health over time and across generations. ${ }^{20}$ 25-28 34

\section{TRADITIONAL THEORETICAL APPROACHES TO IMMIGRANT HEALTH \\ The cultural framework}

While the literature provides evidence in support of an initial healthy effect and a subsequent decline in health, the mechanisms underlying this health transition are still poorly understood. The most dominant explanation typically comes from the cultural framework that views culture as the primary determinant of individual level health behaviours. According to this view, culture impinges on health outcomes via influencing social networks and individual health behaviours (eg, smoking, drinking, calorie-dense diet and less physical activity). As the immigrants arrive in a new society, they abandon the cultural practices of their country of origin and quickly adapt to those from the host country, leading to a progressive deterioration of their health status. ${ }^{35}$ Central to the cultural explanation is the concept of acculturation, an individual level process in which immigrants take on the culture and habits of the mainstream population. To the extent that this process influences health risk behaviours, acculturation is negatively associated with health. ${ }^{4}$

The acculturation approach is often critiqued to be empirically deficit since it loosely defines and operationalises the variables of culture. Also, it holds an ethnocentric view by assuming a mainstream culture toward 
which the immigrants or minority groups are presumed to be acculturating. ${ }^{4}$ Moreover, a core criticism against the acculturation model is that it takes a victim-blaming approach by putting the onus on the individuals. In this approach, culture is seen to be embedded within the individual rather than a socially constructed system ${ }^{18}$ and hence, the responsibility of adopting healthy cultural practices lies with the individual. Studies based on the acculturation framework, therefore, divert the attention from the structural factors, for example, access to healthcare and differences in labour markets, and obscures the role these factors play in the unequal distribution of health outcomes among the immigrants.

\section{The structural framework}

There has increasingly been a shift in focus from the popular acculturation framework to a structural framework that aims to consider the role of macro level social forces in producing and reproducing health inequalities among the immigrants. Current research using this framework tends to focus on access to healthcare or the barriers to accessing healthcare and on health outcomes directly linked to migration status or the living and working conditions of the immigrants. Access to healthcare has been the most common structural factor explored in the literature, ${ }^{36-38}$ although access is considered to be a downstream product of a wider sphere of upstream structural conditions. ${ }^{49}$ The exploration of other institutional and social contexts is relatively limited and mostly concerns the circumstances in the host society (eg, racial discrimination, ${ }^{40}$ lack of legal status ${ }^{41}$ and workplace issues ${ }^{42}$ ), while the country-of-origin circumstances are often overlooked. Only a few studies have attempted to explicitly assess the role of the premigratory conditions in the postmigration health trajectories. ${ }^{734} 43$ Based on panel data from 19 European countries, the study by Bousmah and colleagues ${ }^{34}$ reveals that while the health of the native and foreign-born populations converges over time, there is substantial effect heterogeneity depending on the wealth of the countries of birth. Corroborating this finding, an American study concludes that the level of income inequality at the place of birth negatively affects postmigration health trajectories independent of the national income and life expectancy at the countries of origin. ${ }^{7}$

\section{MODERN THEORETICAL APPROACHES TO IMMIGRANT HEALTH The social determinants of health framework}

The social determinants of health (SDH) approach shifts the focus from the downstream factors to the more upstream 'causes of the causes' in the causal pathways influencing health. ${ }^{39} 44$ Some scholars are arguing for using the untapped potential of the structural framework within the SDH framework that acknowledges the role of social and policy-related factors in shaping individuals' lives and how these factors operate to exclude certain groups and communities not only from medical care but also from various health promoting resources. ${ }^{445}$ Although the WHO-led SDH agenda is an important development to this end, ${ }^{46}$ it does not specifically identify migration as a social determinant of health and is criticised for its overwhelming priority on the 'health gradient' in relation to socioeconomic class at the expense of migration, ethnicity and other categorical determinants of 'health gaps' ${ }^{48}$ However, migration itself serves as a major source of social stratification and substantially contributes to the patterning of health inequalities by influencing other spheres of social life. In the SDH framework, migration is viewed as both a consequence of social determinants such as poverty, unemployment, living conditions and access to social services and a powerful social determinant affecting all of these areas. ${ }^{4}$ Positioning immigration as a key social determinant of health, the SDH approach seeks to explain the health outcomes of immigrants as a function of their social contexts in which they 'are born, grow, live, work and age'. ${ }^{46}$

\section{The intersectionality framework}

Intersectionality is a powerful theoretical approach that aligns itself with the structural/SDH framework and offers important insights into the social structures of power and exclusionary practices. Since the conventional structural and cultural frameworks have limited utility in explaining the multifactorial health disadvantages in the immigrants, intersectionality is now acknowledged as an alternative theoretical perspective that can bring to the fore both premigration and postmigration contextual factors complicating the picture of immigrant health. Originated from black feminist and critical race thoughts, ${ }^{49} 50$ intersectionality has the goal to empower those who are multiply marginalised. Kimberle Crenshaw, a legal scholar and black feminist theorist, is credited with having introduced the term 'intersectionality' in her groundbreaking work in $1989 .{ }^{49}$ Since then, it has travelled a long way from a theory into an analytical tool and from the feminist literature to a variety of academic disciplines including social, behavioural and health sciences. ${ }^{51}$ Crenshaw contended that the single-axis analysis on the basis of sex alone or race alone obscures the multiple dimensions of discrimination and violence experienced by the women of colour ${ }^{49}{ }^{5}$-an argument that serves as the core spirit of intersectionality theory.

Although intersectionality has become a buzzword, there is still a lack of consensus on what might be regarded as an intersectional approach to research. A working definition recently proposed by Else-Quest and Hyde $^{53}$ identified three essential elements of intersectionality: (1) Individuals are characterised by multiple socially constructed categories including gender, race, social class, immigration and these social categories are intertwined. (2) Membership in any of the social categories is linked to power and inequality. (3) Social categories are characteristics of the individuals as well as of the social contexts and as such their meanings are fluid and dynamic. In order for any study to qualify as 
intersectional, it is not enough to merely test interactions between different social strata. ${ }^{54}$ An intersectionalitymotivated study must pay attention to the structures of power, privilege and oppression (eg, sexism, racism and classism) that shape the social experiences of people with different intersectional identities.

Nowadays, there has been a growing interest in the application of the intersectionality scholarship to the investigation of health inequalities. Whereas intersectionality as a framework has gained prominence in qualitative research, suitable methodological strategies in quantitative research have only recently begun to emerge keeping pace with the theoretical advance. ${ }^{54-60}$ Two methodological approaches can be distinguished in the intersectional quantitative literature: the fixed effects approach and the Multilevel Analysis of Individual Heterogeneity and Discriminatory Accuracy (MAIHDA) approach. ${ }^{61}$ The conventional fixed effects model examines intersections either by accommodating the additive main effects of the social strata as well as all possible interaction terms ${ }^{59}$ or by using cross-classified categories representing intersections between social groups (eg, unemployed foreign-born women). ${ }^{62} 63$ This analytical strategy is particularly useful when the dimensions of identity are relatively few. However, as more categories of identity, position and social process are added to the analysis, the number of parameters grows geometrically since the model has to allow all possible combinations of first, second and higher order interaction terms. This inevitably gives rise to a number of methodological concerns regarding model fit and parsimony, reliability of estimates due to low statistical power in some intersectional strata, and the issue of interpretability of the parameters. 5960

Most of the limitations associated with the fixed effects approach are effectively handled by a multilevel intersectional approach, termed as MAIHDA, which is a recent methodological innovation ${ }^{5960} 64$ and is hailed as the 'gold standard' for investigating health inequalities at the intersection of multiple social dimensions. ${ }^{61}$ Multilevel modelling is typically used to account for clustering or similarity between individuals, a phenomenon induced by a shared context. The intersectional MAIHDA is a two-level hierarchical model in which the individuals are nested within the macro societal context represented by a matrix of intersectional social strata which is defined by the unique combinations of all social identities or variables considered in the analysis. While the characteristics such as gender, race, class and migration status are modelled as individual-level variables in the fixed effects or the classical multilevel approach, the same variables are explicitly modelled as the properties of the social context in the MAIHDA approach. The practical advantages of the MAIHDA model over the conventional model are that the former adjusts for sample sizes by default and assesses interaction effects, without having to fit any interaction terms, through an estimation of stratalevel residuals. ${ }^{59} 60$
An intersectional approach to migrant health does not require an entirely new set of methods. The existing theoretical and methodological tools underpinning the intersectionality framework can be extremely useful in the immigrant health context, particularly to delve deeply into the paradoxical 'healthy immigrant effect' frequently reported in the literature which might be due in part to immigrant heterogeneity that is often unaccounted for. It is evident that the intersectionality framework calls for a thorough and rigorous investigation of the complex interactions between migration status, marginalisation processes and other forms of discrimination in the production of health inequalities. ${ }^{35}$ The plausibility that the effects of migration on health conditions are altered by the effects of other social identities and positions ${ }^{65}$ requires an increased attention to the ways in which different axes of social stratification, for example, migration status, gender, race/ethnicity, socioeconomic position, sexual orientation, disability and religion intersect with each other. The demand of a broad intersectional approach to migration is to attend to the hierarchy of social determinants prevailing across the whole migratory trajectory, that is, the determinants originating from the countries of origin, transit and destination. ${ }^{66}$

\section{CONCLUSIONS}

While the decision of migration is influenced by a complex interlocking of a wide variety of economic, social, political and environmental stressors, there has been a growing awareness to put these factors into the broader context of globalisation and climate change within which international migration now occurs. Globalisation promotes growth and development but at the cost of widening inequalities and environmental deterioration which, in turn, stimulate and sometimes force people to move in search of better life chances and a better living environment. Therefore, the contemporary upsurge in international migration is a visible consequence of globalisation. The interplay between globalisation and environment in combination with the local socio-political contexts has reportedly accelerated this trend in recent times, with human-induced climate change emerging as a dominant factor that is likely to drive population movements in the foreseeable future.

If migration would not impact on health and health inequalities, the growing phenomenon of migration would just be an issue of academic interest without being a genuine cause for public health concern. However, migration does affect health through processes that systematically exacerbate vulnerabilities to health hazards, thereby challenging the global health equity movement. The migrants can actually be a healthier group compared to both the population they join and the population they leave behind, with the exception of the forced migrants. However, the healthy profile of the migrants tends to be offset over time as they settle in the new society. 
In immigrant health research, the hegemonic cultural perspective explains the immigrant health transition as having to do with their acculturating towards the lifestyles and health-risk behaviours of the mainstream population. The acculturation framework, however, ignores the structural factors affecting the social and economic integration of the migrants who are discriminated and marginalised through the process of 'othering'. The structural perspective came up with the promise to explore the structural factors, but a full examination of such factors is currently hampered due to an overwhelming focus on access to healthcare and inadequate attention to institutional and social contexts. In order to do justice to the phenomenon of increasing heterogeneity in the immigrant populations and the complexity of the link between migration and health, the structural paradigm must turn the spotlight on the wider sphere of SDH in which migration needs to be positioned as a social determinant in its own right. The intersectionality framework has the potential to further enrich immigrant health research through greater attention to the upstream causal processes and going beyond the master category of migration status to multi-level social categories that intersect to produce health inequalities.

Acknowledgements This article was produced during the author's stay at Stockholm University in Sweden, thanks to a Swedish Institute scholarship. The author wishes to express sincere gratitude to Dr Karl Gauffin and Dr Andrea Dunlavy at Stockholm University for providing critical feedback on an earlier version of the manuscript. The author also acknowledges the valuable comments received from three anonymous reviewers.

Contributors $\mathrm{MZH}$ is the sole author.

Funding The authors have not declared a specific grant for this research from any funding agency in the public, commercial or not-for-profit sectors.

Competing interests None declared.

Patient consent for publication Not required.

Provenance and peer review Not commissioned; externally peer reviewed.

Data availability statement № additional data are available.

Open access This is an open access article distributed in accordance with the Creative Commons Attribution Non Commercial (CC BY-NC 4.0) license, which permits others to distribute, remix, adapt, build upon this work non-commercially, and license their derivative works on different terms, provided the original work is properly cited, appropriate credit is given, any changes made indicated, and the use is non-commercial. See: http://creativecommons.org/licenses/by-nc/4.0/.

ORCID iD

Muhammad Zakir Hossin http://orcid.org/0000-0002-9078-419X

\section{REFERENCES}

1 International Organization for Migration (IOM). World migration report 2020, 2020. Available: https://publications.iom.int/system/files/pdf/ wmr_2020.pdf

2 International Organization for Migration (IOM). How the world views migration, 2015. Available: https://publications.iom.int/system/files/ how_the_world_gallup.pdf

3 International Organization for Migration (IOM), World Health Organization (WHO), United Nations Human Rights (UNHR). International migration, health and human rights, 2013. Available: https://www.ohchr.org/Documents/Issues/Migration/WHO_IOM_ UNOHCHRPublication.pdf

4 Castañeda H, Holmes SM, Madrigal DS, et al. Immigration as a social determinant of health. Annu Rev Public Health 2015;36:375-92.
5 Hjern A. Migration and public health: health in Sweden: the National public health report 2012. Chapter 13. Scand J Public Health 2012;40:255-67.

6 De Maio FG. Immigration as pathogenic: a systematic review of the health of immigrants to Canada. Int J Equity Health 2010;9:27.

7 Maskileyson D. Health trajectories of immigrants in the United States: does income inequality of country of origin matter? Soc Sci Med 2019;230:246-55.

8 McMichael C, Barnett J, McMichael AJ. An ill wind? climate change, migration, and health. Environ Health Perspect 2012;120:646-54.

9 Black R, Adger WN, Arnell NW, et al. The effect of environmental change on human migration. Glob Environ Chang 2011;21:S3-11.

10 Black R, Bennett SRG, Thomas SM, et al. Migration as adaptation. Nature 2011;478:447-9.

11 Feachem RGA. Globalisation is good for your health, mostly. BMJ 2001;323:504-6.

12 Labonté R, Schrecker T. Globalization and social determinants of health: the role of the global marketplace (Part 2 of 3). Global Health 2007;3:6.

13 Black R, Natali C, Skinner J. Migration and inequality. World Bank, 2006.

14 Bastia T. Migration and inequality: an introduction. In: Bastia T, ed. Migration and inequality. New York: Routledge, 2013: 4-6.

15 Zimmerman C, Kiss L, Hossain M. Migration and health: a framework for 21 st century policy-making. PLoS Med 2011;8:e1001034.

16 Hugo G. Environmental concerns and international migration. Int Migr Rev 1996;30:105-31.

17 Grove NJ, Zwi AB. Our health and theirs: forced migration, othering, and public health. Soc Sci Med 2006;62:1931-42.

18 Viruell-Fuentes EA. Beyond acculturation: immigration, discrimination, and health research among Mexicans in the United States. Soc Sci Med 2007;65:1524-35.

19 Gostin LO, Roberts AE. Forced migration: the human face of a health crisis. JAMA 2015;314:2125-6.

20 Jatrana S, Pasupuleti SSR, Richardson K. Nativity, duration of residence and chronic health conditions in Australia: do trends converge towards the native-born population? Soc Sci Med 2014;119:53-63.

21 Malmusi D, Borrell C, Benach J. Migration-related health inequalities: showing the complex interactions between gender, social class and place of origin. Soc Sci Med 2010;71:1610-9.

22 Kennedy S, Kidd MP, McDonald JT, et al. The healthy immigrant effect: patterns and evidence from four countries. J Int Migr Integr 2015;16:317-32.

23 McDonald JT, Kennedy S. Insights into the 'healthy immigrant effect': health status and health service use of immigrants to Canada. Soc Sci Med 2004;59:1613-27.

24 Ronellenfitsch U, Razum O. Deteriorating health satisfaction among immigrants from Eastern Europe to Germany. Int $J$ Equity Health 2004;3:1-10.

25 Uretsky MC, Mathiesen SG. The effects of years lived in the United States on the general health status of california's foreign-born populations. J Immigrant Health 2007;9:125-36.

26 Newbold KB, Danforth J. Health status and Canada's immigrant population. Soc Sci Med 2003;57:1981-95.

27 Chiswick BR, Lee YEWL, Miller PW. Immigrant selection systems and immigrant health. Contemp Econ Policy 2008;26:555-78.

$28 \mathrm{Wu} Z$, Schimmele CM. The healthy migrant effect on depression: variation over time? Can Stud Popul 2005;32:271-95.

29 Abraído-Lanza AF, Dohrenwend BP, Ng-Mak DS, et al. The Latino mortality paradox: a test of the "salmon bias" and healthy migrant hypotheses. Am J Public Health 1999;89:1543-8.

30 Constant AF, García-Muñoz T, Neuman S, et al. A "healthy immigrant effect" or a "sick immigrant effect"? Selection and policies matter. Eur J Heal Econ 2018;19:103-21.

31 Razum O. Commentary: of salmon and time travellers--musing on the mystery of migrant mortality. Int J Epidemiol 2006;35:919-21.

32 Razum O, Zeeb H, Akgün HS, et al. Low overall mortality of Turkish residents in Germany persists and extends into a second generation: merely a healthy migrant effect? Trop Med Int Health 1998;3:297-303.

33 Andersson G, Drefahl S. Long-distance migration and mortality in Sweden: testing the salmon bias and healthy migrant hypotheses. Popul Space Place 2017;23:e2032.

34 Bousmah M-A-Q, Combes J-BS, Abu-Zaineh M. Health differentials between citizens and immigrants in Europe: a heterogeneous convergence. Health Policy 2019;123:235-43.

35 Viruell-Fuentes EA, Miranda PY, Abdulrahim S. More than culture: structural racism, intersectionality theory, and immigrant health. Soc Sci Med 2012;75:2099-106. 
36 Almeida LM, Caldas J, Ayres-de-Campos D, et al. Maternal healthcare in migrants: a systematic review. Matern Child Health $\mathrm{J}$ 2013;17:1346-54.

37 Hacker K, Anies M, Folb BL, et al. Barriers to health care for undocumented immigrants: a literature review. Risk Manag Healthc Policy 2015;8:175-83.

38 Suphanchaimat R, Kantamaturapoj K, Putthasri W, et al. Challenges in the provision of healthcare services for migrants: a systematic review through providers' lens. BMC Health Serv Res 2015;15:1-14.

39 Braveman P, Egerter S, Williams DR. The social determinants of health: coming of age. Annu Rev Public Health 2011;32:381-98.

40 Yip T, Gee GC, Takeuchi DT. Racial discrimination and psychological distress: the impact of ethnic identity and age among immigrant and United States-born Asian adults. Dev Psychol 2008;44:787-800.

41 Sullivan MM, Rehm R. Mental health of undocumented Mexican immigrants: a review of the literature. ANS Adv Nurs Sci 2005;28:240-51.

42 Sterud T, Tynes T, Mehlum IS, et al. A systematic review of working conditions and occupational health among immigrants in Europe and Canada. BMC Public Health 2018;18:1-15.

43 Hollander A-C, Bruce D, Ekberg J, et al. Longitudinal study of mortality among refugees in Sweden. Int $J$ Epidemiol 2012;41:1153-61.

44 Braveman P, Gottlieb L. The social determinants of health: it's time to consider the causes of the causes. Public Health Rep 2014:129:19-31.

45 Wallace SP, Young M-EDT, Rodríguez MA, et al. A social determinants framework identifying state-level immigrant policies and their influence on health. SSM Popul Health 2019;7:100316.

46 Marmot M, Friel S, Bell R, et al. Closing the gap in a generation: health equity through action on the social determinants of health Lancet 2008;372:1661-9.

47 Marmot M. Review of social determinants and the health divide in the WHO European region: final report, 2013.

48 Ingleby D. Ethnicity, Migration and the 'Social Determinants of Health' Agenda*. Psychosoc Interv 2012;21:331-41.

49 Crenshaw K. Demarginalizing the intersection of race and sex: a black feminist critique of antidiscrimination doctrine, feminist theory, and antiracist politics. University of Chicago Legal Forum, 1989: 139-68.

50 Collins PH. Black feminist thought: knowledge, consciousness, and the politics of empowerment. 97. New York: Routledge, 1990.

51 Carbado DW, Crenshaw KW, Mays VM, et al. Intersectionality: mapping the movements of a theory. Du Bois Rev 2013;10:303-12.

52 Crenshaw K. Mapping the margins: intersectionality, identity politics, and violence against women of color. Stanford Law Rev 1991;43:1241.
53 Else-Quest NM, Hyde JS. Intersectionality in quantitative psychological research: theoretical and epistemological issues. Psychol Women Q 2015;40:155-70.

54 Green MA, Evans CR, Subramanian SV. Can intersectionality theory enrich population health research? Soc Sci Med 2017;178:214-6.

55 Richman LS, Zucker AN. Quantifying intersectionality: an important advancement for health inequality research. Soc Sci Med 2019;226:246-8

56 Hankivsky O, Reid C, Cormier R, et al. Exploring the promises of intersectionality for advancing women's health research. Int J Equity Health 2010;9:5-15.

57 Scheim Al, Bauer GR. The intersectional discrimination index: development and validation of measures of self-reported enacted and anticipated discrimination for intercategorical analysis. Soc Sci Med 2019;226:225-35.

58 Bauer GR, Scheim Al. Methods for analytic intercategorical intersectionality in quantitative research: discrimination as a mediator of health inequalities. Soc Sci Med 2019;226:236-45.

59 Evans CR. Adding interactions to models of intersectional health inequalities: comparing multilevel and conventional methods. Soc Sci Med 2019;221:95-105

60 Evans CR, Williams DR, Onnela J-P, et al. A multilevel approach to modeling health inequalities at the intersection of multiple social identities. Soc Sci Med 2018;203:64-73.

61 Merlo J. Multilevel analysis of individual heterogeneity and discriminatory accuracy (MAIHDA) within an intersectional framework. Soc Sci Med 2018;203:74-80.

62 Hollander A-C, Bruce D, Ekberg J, et al. Hospitalisation for depressive disorder following unemployment--differentials by gender and immigrant status: a population-based cohort study in Sweden. J Epidemiol Community Health 2013;67:875-81.

63 Wamala S, Ahnquist J, Månsdotter A. How do gender, class and ethnicity interact to determine health status? J Gend Stud 2009:18:115-29.

64 Jones K, Johnston R, Manley D. Uncovering interactions in multivariate contingency tables: a multi-level modelling exploratory approach. Methodol Innov 2016:9:205979911667287.

65 Nazroo J, lley K. Ethnicity, migration and mental health: the role of social and economic inequalities. In: Bhugra D, Gupta S, eds. Migration and mental health. New York: Cambridge University Press, 2011: 79-98

66 Llácer A, Zunzunegui MV, del Amo J, et al. The contribution of a gender perspective to the understanding of migrants' health. $J$ Epidemiol Community Health 2007;61:ii4-10. 